\title{
The Montreal Climate Summit: Starting the Kyoto Business and Preparing for post-2012
}

\author{
The Kyoto Protocol's First Meeting of the Parties (MOP 1) and \\ COP 11 of the UNFCCC
}

Bettina Wittneben, Wolfgang Sterk, Hermann E. Ott and Bernd Brouns*

\section{Introduction}

The first Meeting of the Parties to the Kyoto Protocol $(\text { MOP } 1)^{1}$ took place from 28 November to 10 December 2005 in Montreal, in conjunction with the eleventh meeting of the Conference of the Parties to the Framework Convention on Climate Change (COP 11). This meeting signifies a successful start into a new era of international climate policy: The Kyoto Protocol, which in the past had been sometimes declared as being dead, ${ }^{2}$ has become operational, including its flexible mechanisms and its non-compliance procedure. Negotiations have started to move forward towards 'Kyoto 2', an agreement for the time after 2012 when the Protocol's first commitment period expires.

More than 10,000 participants made this the largest climate change conference ever, exceeding even the previous record set by COP 3 , which had seen the adoption of the Kyoto Protocol in 1997. The Canadian Environment Minister Stéphane Dion, serving as President to the summit, termed the challenges of the meeting the 'Three Is', drawing on an idea by former Executive Secretary Michael Zammit Cutajar: Implementation, Improvement and Innovation. The first challenge (Implementation) entailed in particular the adoption of the Marrakesh Accords, the agreements reached at COP 7 in Marrakesh that set out the detailed rules for making the Kyoto Protocol operational. The second challenge (Improvement) referred to improving the work of the Framework Convention and the Kyoto Protocol in the near future. The third and most important challenge (Innovation) referred to the further evolution of the regime.

This paper will provide an account of the main developments in Montreal along the lines of the 'Three Is'. However, due to the importance of the issue and the supposed interest of the reader, the politically most noted developments regarding the post-2012 process (Innovation) are described at the beginning of this report. It is followed by the developments regarding Implementation and Improvement. The paper concludes with an assessment and outlook on international climate policy.

\section{Innovation - paving the way for post-2012 negotiations}

The reduction obligations contained in the Protocol expire in 2012 and are rather moderate compared to the efforts needed to prevent 'dangerous' climate change, the Framework Convention's ultimate objective. The recent years have therefore seen intensive debates on the development of mitigation commitments beyond the Protocol's first commitment period in the research community and in civil society, but also increasingly among decision-makers. ${ }^{3}$ However, before the Montreal conference these post-2012 discussions had not been part of the formal negotiations. An early attempt by the EU to transfer this issue onto the agenda of negotiations failed at COP 8 in New Delhi (2002) and caused serious disturbances in the relationship between the $\mathrm{EU}$ and the developing countries, organised in the Group of 77 (G-77) \& China. ${ }^{4}$ Last year at COP 10 in Buenos Aires, long-lasting, high-level negotiations

\footnotetext{
* The authors all work with the Wuppertal Institute for Climate, Environment and Energy. All authors contributed equally to the text.

1 For the sake of brevity and to minimise complexity the abbreviation MOP is used instead of COP/MOP for 'the Conference of the Parties (to the Convention) serving as the meeting of the Parties (to the Protocol)'

2 See Meinhard Doelle: The Cat Came Back, or the Nine Lives of the Kyoto Protocol (unpublished manuscript; http://law.dal.ca/files/ the_cat_came_back_or_the_nine_lives_of_the_kyoto_protocol.pdf.

3 See, for example, http://www.wupperinst.org/COP11/index.html; http://www.fiacc.net

4 See Ott, 'Global Climate', 13 Yearbook of International Environmental Law 2002, pp. 261-270.
} 
only resulted in an informal 'Seminar of Governmental Experts' that was not formally linked to the negotiation process. ${ }^{5}$

The conditions in Montreal, however, were far more promising for getting 'Innovation' processes within the climate regime started. This was, first, due to a legal provision contained in the Protocol: Article 3.9 requests the MOP to initiate considerations on post-2012 commitments for Annex I Parties $^{6}$ at least seven years before the end of the first commitment period, i.e. in 2005. Second, negotiations under the MOP only involve the like-minded' group of Parties to the Kyoto Protocol, thus excluding the US delegation that has been a stumbling block in past negotiations. Thirdly, more than ever before, private sector actors involved in the evolving carbon markets put pressure on the Kyoto Parties to send a clear signal on mid- and long-term perspectives at MOP 1 . Last but not least, recent results of climate models combined with emissions trends and projections in recent years have rendered it more obvious that mitigation activities

5 Ott/Brouns/Sterk/Wittneben, 'It Takes Two to Tango: Climate Policy at COP 10 in Buenos Aires and Beyond', JEEPL 2005, pp. 84-91.

6 Throughout this Article, Annex I Party means a country included in Annex I to the United Nations Framework Convention on Climate Change (UNFCCC) that has ratified the UNFCCC or has additionally ratified the Kyoto Protocol and thus has a commitment inscribed in Annex B, Kyoto Protocol. These are mainly the traditional 'industrialised' countries. The term non-Annex I Party refers to a Party that either ratified the UNFCCC or both, FCCC and Kyoto Protocol but is not included in these Annexes. These are mainly the traditional 'developing' countries.

7 See, for example, UNFCCC, Key GHG Data, Greenhouse Gas Emissions Data for 1990-2003 submitted to the United Nations Framework Convention on Climate Change, Bonn 2005; Den Den Elzen/Meinshausen, Meeting the EU $2{ }^{\circ} \mathrm{C}$ climate tarket: global and regional emission implications. Bilthoven: Netherlands Environmental Assessment Agency 2005. Department for Environment, Food and Rural Affairs, Avoiding Dangerous Climate Change, Scientific Symposium on Stabilisation of Greenhouse Gases, 1 to 3 February 2005, Met Office, Exeter, United Kingdom, Executive Summary of the Conference Report, and Schellnhuber (ed.), Avoiding Dangerous Climate Change, Cambridge Univ. Press 2006.

8 Article 3, paragraph 9, of the Kyoto Protocol: consideration of commitments for subsequent periods for Parties included in Annex I to the Convention, Draft decision proposed by Jamaica on behalf of the Group of 77 and China, FCCC/KP/CMP/2005/CRP.3, 2 December 2005.

9 Article 3, paragraph 9, of the Kyoto Protocol: consideration of commitments for subsequent periods for Parties included in Annex I to the Convention Draft decision proposed by the United Kingdom of Great Britain and Northern Ireland on behalf of the European Community and its Member States, FCCC/KP/CMP/2005/CRP.3, 2 December 2005; Article 3, paragraph 9, of the Kyoto Protocol: consideration of commitments for subsequent periods for Parties included in Annex I to the Convention, Draft decision proposed by Japan,

FCCC/KP/CMP/2005/CRP.3, 2 December 2005. have to be strengthened far beyond the Kyoto obligations. ${ }^{7}$ The Canadian Presidency attempted to pursue these tasks with a 'dual track' approach: Apart from initiating a negotiation process under Article 3.9 KP, President Dion also pushed for a decision under the Climate Convention to kick-start a process with broader participation beyond the 'Kyoto Ratifiers'.

\section{The Kyoto track}

There were mainly two points of contention during the negotiations pursuant to Article 3.9. The first was of a more procedural nature, involving questions of the institutional setting and the timeline for negotiations. From the outset of the negotiations, the G-77 \& China, were quite clear on their position to establish an open-ended ad hoc working group of Kyoto Parties that should complete its work with a view to adopt decisions on future commitments at MOP 4 in 2008. ${ }^{8}$ Such an ad hoc working group has the benefit that it can meet more often than the MOP as well as have chair and its own agenda. This enables the group to focus solely on the issue addressed in its mandate and to formulate draft decisions for the MOP. The G-77 \& China emphasised that progress under Article 3.9 $\mathrm{KP}$ was seen as a crucial test of the industrialised countries' willingness to take the lead and of their faith in the Protocol. The proposals put forward by the EU and Japan in the first week were much weaker on the procedural aspects and did not mention any timeline or negotiation body. ${ }^{9}$ However, these first proposals were partly strategic positions to have a bargaining chip on the second point of contention: Which countries should take on commitments?

Although Article $3.9 \mathrm{KP}$ only addresses future commitments of Annex I Parties, most industrialised countries aimed at broadening the process to other Parties. They proposed to include a reference in the mandate to Article $9 \mathrm{KP}$. This article prescribes a general review of the adequacy of the Protocol at regular intervals, with the first review starting at MOP 2. This review might be used to also consider future actions by developing countries. The G-77 \& China, however, clearly stated in their proposal that 'no new commitment shall be introduced under the Protocol for Parties not included in Annex I' and therefore refused to include 
any reference to Article $9 \mathrm{KP}$. During negotiations behind closed doors almost all industrialised countries finally accepted the G-77 \& China position that from a legal perspective Article $3.9 \mathrm{KP}$ was not the suitable place to discuss broader participation. They subsequently aimed at a separate decision to prepare the Article 9 review and focused more on the second track of negotiations under the Convention to initiate a process with broader participation.

Industrialised countries also agreed to the establishment of an 'open-ended ad hoc working group of Parties to the Kyoto Protocol' whereas the G-77 \& China had to give up their 2008 timeline in favour of a less specific phrase that negotiations should be completed 'in time to ensure that there is no gap between the first and the second commitment period'. This formula appears to be sufficiently precise in order to mandate the finalisation of negotiations before 2009, since it will take at least two years to complete the ratification process for the new commitments. Nevertheless, it took three lengthy night sessions before Parties forwarded a draft decision to the COP Presidency, mainly because Russia insisted on including a provision to give non-Annex I Parties the opportunity to take on voluntary commitments. This was, however, not only politically unacceptable for the G-77 \& China but also legally impossible as Article $3.9 \mathrm{KP}$ explicitly refers only to Annex I countries. The MOP finally agreed to request President Dion to hold consultations on the Russian proposal and to report his conclusions to MOP 2, while the decision on Article $3.9 \mathrm{KP}$ was adopted in the form already agreed on 36 hours earlier. $^{10}$

Subsequently, the MOP agreed to include a reference to Article $9 \mathrm{KP}$ in its report inviting Parties to submit relevant information and views on the review of the Protocol by 1 September 2006. ${ }^{11}$ The second MOP will receive a report by the Secretariat on these submissions. If it does not come to any final conclusions, from next year onwards there might thus be a third process on the future of the climate regime, dealing with the review of the Kyoto Protocol as a whole.

\section{The Convention track}

Negotiations on further commitments under the Kyoto Protocol were complemented by an initiative of COP President Dion to start a post-2012 process under the Convention. The underlying motivation for this 'dual track' approach was clearly visible: a COP decision allows for broader coverage, both on substance (also including adaptation to the impacts of climate change and a focus on technologies and development goals) and participation (also addressing Convention Parties that have not yet ratified the Protocol). Environmental groups, however, claimed that the Convention track was not very promising as the US administration had announced many times before and at the conference that 'post-2012' was a non-issue for them in Montreal. These concerns were partly confirmed when the COP President presented his proposal for a COP decision on 6 December. ${ }^{12}$ It only included a series of workshops on a broad range of issues for long-term cooperative action to address climate change.

Further negotiations followed but expectations were quite low, especially after the US delegates walked out of the negotiations on Thursday night. Given these circumstances it came as a surprise for many observers that negotiations on the President's proposal were finished even a few hours before Parties came to an agreement on the 'Kyoto track'. However, the final COP decision is rather weak. It is not even called a process but instead a 'dialogue on long-term cooperative action to address climate change by enhancing implementation of the Convention.' ${ }^{13}$ The Parties acknowledge that 'the global nature of climate change calls for the widest possible cooperation and participation in an effective and appropriate international response'. However, due to the insistence of the US negotiators, the decision also requires that the dialogue should not prejudice 'any future negotiations, commitments, process, framework or mandate under the Convention' and is rather 'an open and non-binding exchange of views $[\ldots]$ and will not open to any negotiations leading to new commitments'. Starting with a first round of submissions by Parties due 15 April 2006,

10 Draft decision -/CMP.1, Consideration of commitments for subsequent periods for Parties included in Annex I to the Convention under Article 3, paragraph 9, of the Kyoto Protocol, FCCC/KP/CMP/2005/L.8/Rev.1, 10 December 2005.

11 See the conference report on the website of the UNFCCC Secretariat: http://www.unfccc.int.

12 Draft decision on a process for discussions on long-term cooperative action to address climate change, Proposal by the President, FCCC/CP/2005/CRP.1, 6 December 2005.

13 Draft decision -/CP.11, Dialogue on long-term cooperative action to address climate change by enhancing implementation of the Convention, FCCC/CP/2005/L.4/Rev.1, 9 December 2005. 
the dialogue will continue until COP 13 and will take place in up to four workshops that address future activities in a broad range of areas including adaptation and mitigation activities.

Although this dialogue will not directly result in 'long-term cooperative action' it will, at least, provide a forum for an exchange of views and information. Considering the starting point of negotiations when two major actors, the G-77 \& China and the US, were not very keen on negotiating mandatory future action, this dialogue is probably the best agreement that was possible. The 'Seminar of Governmental Experts' (SOGE) in May 2005 that was not even officially linked to the negotiating process indicates the potential value of such a dialogue to lead to a better understanding of each other's positions. In the case of Papua New Guinea, it even had a direct effect on official negotiations as the seminar prepared the ground for the submission of a proposal on avoiding deforestation in developing countries to the COP.

\section{The Papua New Guinea proposal}

This proposal by Papua New Guinea resulted in another future oriented process that started in Montreal and falls under the term 'Innovation': Based on its SOGE presentation in May 2005, Papua New Guinea, supported by eight other countries from Latin America and Africa, requested the secretariat to add the item 'reducing emissions from deforestation in developing countries: approaches to stimulate action' to the COP agenda. Highlighting that a large share of global emissions results from deforestation but that neither the Convention nor the Protocol currently adequately addresses these emissions, a joint submission by Papua New Guinea and Costa Rica emphasised the need for innovative approaches in this area as a major requirement for achieving the objective of the Climate Convention to prevent 'dangerous climate

14 Reducing emissions from deforestation in developing countries: approaches to stimulate action, Submissions from Parties, FCCC/CP/2005/MISC.1, 11 November 2005.

15 Reducing emissions from deforestation in developing countries: approaches to stimulate action, Draft conclusions proposed by the President, FCCC/CP/2005/L.2, 6 December 2005.

16 For an account of the negotiations leading to the adoption of the Kyoto Protocol and an analysis of its content, see Oberthür/Ott, The Kyoto Protocol, International Climate Policy for the $21 \mathrm{st}$ Century, Berlin 1999. change.. ${ }^{14}$ They proposed a 'fair and equitable access to carbon markets' as a condition for substantial engagement and made two suggestions: either to elaborate an optional Protocol under the Climate Convention or to make forest conservation activities eligible under the CDM.

The COP decided to submit this issue for further deliberations to SBSTA. It invited Parties to submit their views on substance and recommendations on the further process by 31 March 2006 for consideration at SBSTA-24 in May 2006. It furthermore proposed that a workshop take place before SBSTA-25 in November 2006. ${ }^{15}$ The issue will thus be dealt with as part of the post-2012 package.

Accounting forest conservation activities as emission reductions is not as simple as it seems at a first glance. Having in mind the controversial debate on 'avoided deforestation' in the run-up to COP 7 in Marrakesh, there are many factors that need to be taken into account when attempting to protect forest areas (e.g. property rights, permanence, monitoring). However, the Papua New Guinea initiative addresses one of the major omissions in the current design of the climate regime.

\section{Implementation - completing the Kyoto framework and preparing for adaptation}

\section{Adopting the Marrakesh Accords}

The Kyoto Protocol as adopted in 1997 established absolute quantitative emission limitation and reduction commitments for industrialised countries as well as market mechanisms - international emission trading, the Clean Development Mechanism and Joint Implementation - that are intended to achieve these commitments in a cost-effective manner. ${ }^{16}$ However, the Kyoto Protocol is rather incomplete regarding the details required for its implementation. It took another four years until Parties agreed at COP 7 in Marrakesh on a detailed 'rule book' to the Kyoto Protocol. The Marrakesh Accords comprise more than 200 pages including, among others, rules and guidelines for making the Kyoto mechanisms operational, the accounting of emissions as well as of removals of greenhouse gases from the atmosphere resulting from land-use change and forestry activities, and additional requirements for greenhouse gas inventories. They also comprise 
decisions supporting developing countries through capacity building, technology transfer, and the establishment of three new funds that mainly serve to assist developing countries to adapt to the impacts of climate change: the Least Developed Countries Fund (LDCF), the Special Climate Change Fund (SCCF), and the Adaptation Fund (AF) ${ }^{17}$

However, since only the meeting of the Parties to the Kyoto Protocol (MOP) is legally competent to adopt Kyoto-related decisions, COP 7 formally adopted only draft decisions and forwarded these to the MOP for final adoption. On 30 November 2005 , the third day of the Montreal conference, it took only a few minutes for the MOP to unanimously adopt the 21 decisions that had been forwarded from the COP, thereby moving a major step forward towards the achievement of Dion's first ' $\mathrm{I} .{ }^{18}$ Only the decision on the compliance regime was postponed due to a proposal by Saudi Arabia that it should be implemented as an amendment to the Protocol rather than by a MOP decision.

\section{Compliance regime: facilitation and enforcement}

The compliance procedure was part of the package negotiated in Marrakesh and although it was finalised regarding the substance, it could not be adopted due to different views regarding the legal form of the agreement. These differences quickly resurfaced in Montreal: Whereas Saudi Arabia had tabled a proposal to adopt the procedure as an amendment to the Protocol, ${ }^{19}$ Japan was strictly opposed to this idea and favoured the adoption of the compliance procedure by way of a simple decision of the MOP. The difference of these two approaches is explained by looking at the 'compliance regime' provisions in Article 18 of the Kyoto Protocol, which states in its first sentence that the MOP should at its first session 'approve appropriate and effective procedures' and determines in its second sentence that 'any procedures and mechanisms entailing "binding consequences" shall be adopted by means of an amendment to this Protocol'.

There has been some discussion in the literature on the meaning of 'binding' and the legal nature of decisions versus amendments. ${ }^{20}$ Suffice it to say that the degree of 'bindingness' depends in large part on the value given to a procedure by the Parties themselves. The Non-compliance Procedure of the
Montreal Protocol on Substances that Deplete the Ozone Layer (1987), ${ }^{21}$ for example, was adopted by way of a decision and can deliver rulings that are binding on the countries concerned. Since the Parties are the 'Masters of the Treaty', they are in the position to enforce the consequences whatever legal character is given to the process. ${ }^{22}$

When Saudi Arabia proposed the adoption by way of an amendment, therefore, it proposed (on the surface) a 'tougher' procedure that would clarify its character. This clarity would come with a downside, though. According to Article 20 of the Kyoto Protocol, amendments shall be adopted by the MOP and afterwards have to be ratified by three fourths of the Parties to come into force. This takes time, and adopting the compliance procedure only by way of an amendment would thus leave the

17 For an analysis see Ott, 'Global Climate', 12 Yearbook of International Environmental Law 2001, pp. 211-221; Yamin/Depledge, The International Climate Change Regime, A Guide to Rules, Institutions and Procedures, Cambridge 2004.

18 Compendium of draft decisions forwarded for adoption by the Conference of the Parties serving as the meeting of the Parties to the Kyoto Protocol at its first session, Note by the secretariat, FCCC/KP/CMP/2005/3， 1 August 2005; Compendium of draft decisions forwarded for adoption by the Conference of the Parties serving as the meeting of the Parties to the Kyoto Protocol at its first session, Note by the secretariat, Addendum, Decisions concerning land use, land-use change and forestry, and matters relating to Article 3, paragraph 14, of the Kyoto Protocol, FCCC/KP/CMP/2005/3/Add.1, 1 August 2005; Compendium of draft decisions forwarded for adoption by the Conference of the Parties serving as the meeting of the Parties to the Kyoto Protocol at its first session, Note by the secretariat, Addendum, Decisions concerning guidelines under Articles 5, 7 and 9 of the Kyoto Protocol, FCCC/KP/CMP/2005/3/Add.2, 1 August 2005; Compendium of draft decisions forwarded for adoption by the Conference of the Parties serving as the meeting of the Parties to the Kyoto Protocol at its first session, Note by the secretariat,

Addendum, Decisions concerning mechanisms pursuant to Articles 6, 12 and 17 of the Kyoto Protocol, and modalities for the accounting of assigned amounts under Article 7, paragraph 4, of the Kyoto Protocol, FCCC/KP/CMP/2005/3/Add.3, 3 August 2005; Compendium of draft decisions forwarded for adoption by the Conference of the Parties serving as the meeting of the Parties to the Kyoto Protocol at its first session, Note by the secretariat, Addendum, Decisions concerning the modalities and procedures for a clean development mechanism, as defined in Articles 12 of the Kyoto Protocol, FCCC/KP/CMP/2005/3/Add.4, 3 August 2005.

19 Proposal by Saudi Arabia to amend the Kyoto Protocol, Note by the Secretariat, FCCC/KP/CMP/2005/2, 26 May 2005.

20 See MacFaul, Adoption of procedures and mechanisms relating to compliance under the Kyoto Protocol: a guide, Vertic Brief No. 6, November 2005.

21 Montreal Protocol on Substances that Deplete the Ozone Layer, 26 ILM 1550 (1987).

22 See Ott, Umweltregime im Völkerrecht. Eine Untersuchung über neue Formen internationaler institutionalisierter Kooperation am Beispiel der Verträge zum Schutz der Ozonschicht und zur Kontrolle grenzüberschreitender Abfallverbringungen, BadenBaden 1998 
Parties without an enforcement mechanism for some years. Second, the amendment would only be binding for those Parties that have ratified it. Proceeding along this path would thus lead to two sets of countries - those subject to a compliance procedure and those that are not.

The European Union and the developing countries apart from Saudi Arabia favoured intermediate positions that involved adopting the compliance procedure by way of a decision first and at the same time initiating a process for the amendment of the Kyoto Protocol according to its Article 18. The extreme positions of Saudi Arabia and Japan (that opposed the adoption of an amendment in principle) were finally overcome by a compromise formulation of Canada and New Zealand. The final wording thus stipulates that the MOP 'approves and adopts' the compliance procedure and that the 'consideration of the issue of an amendment' shall be 'commenced', with a view to 'making a decision' at MOP $3 .{ }^{23}$ This phrase is sufficiently vague to allow finalising the process without prejudice to the outcome - whether to amend the Protocol or not. And it ensures that there is a compliance procedure in place for all Parties from the beginning of the first commitment period.

The annex to the final decision contains the main operational elements of a procedure that has the potential to be an effective instrument for the implementation of the Kyoto Protocol. The decision establishes a Compliance Committee with two branches: a 'facilitative branch' will support a party's efforts to comply with its obligations and an 'enforcement branch' has been set up to monitor compliance with the most important obligations.

The facilitative branch, as the name indicates, is not tasked to enforce compliance but shall support Parties in the fulfilment of their obligations by providing advice and technical or financial assistance. The enforcement branch, on the other hand, has some measures at hand for bringing about compliance, like prohibiting a Party from selling under the emissions trading regime.

Additionally, for every tonne of emissions by which a Party exceeds its target, 1.3 tonnes will be

23 Draft decision -/CMP.1, Procedures and mechanisms relating to compliance under the Kyoto Protocol, FCCC/KP//CMP/2005/L.5, 7 December 2005.

24 Draft decision -/CMP.1, Implementation of Article 6 of the Kyoto Protocol, FCCC/KP//CMP/2005/L.5, 7 December 2005. deducted from its assigned amount for the subsequent commitment period. Finally, the Party not being in compliance will be required to submit a 'compliance action plan' that will be reviewed by the committee. An appeals procedure provides for a review of decisions by the MOP. During the appeals procedure the decisions by the Compliance Committee remain in force - an important detail that strengthens the position of the Committee. Overturning a decision of the Compliance Committee by the MOP and referring the matter back to the Enforcement Branch requires a three-fourths majority. It remains to be seen how the procedure will operate in practice, but it certainly lays a good foundation for the effective enforcement of the Protocol obligations.

\section{Joint Implementation}

According to Article 6 of the Protocol, Annex I Parties can acquire emission reduction units (ERUs) generated by greenhouse gas mitigation projects in other Annex I Parties and count these towards their Kyoto targets. Countries which meet all the criteria for participating in the Protocol's flexible mechanisms qualify for the JI 1st track, which does not require an approval process as complex as under the JI 2nd track. The 1st track therefore was not an issue in Montreal.

Projects in the 2nd track are to be conducted under an international procedure overseen by the JI Supervisory Committee (JISC). Much of the discussion in Montreal focussed on whether to utilise elements from the CDM process in the JI procedures. Annex I Parties wanted to see much of the CDM rules applied to JI to facilitate the functioning of the latter mechanism. Non-Annex I Parties, however, were concerned that climate-friendly investment will flow into JI projects rather than CDM projects. The compromise reached in Montreal included the decision that Designated Operational Entities under the CDM (private certification companies that audit whether projects meet the CDM requirements) will not automatically qualify for evaluating JI 2nd track projects but have to instead apply for accreditation. However, they can serve provisionally until the JISC has taken the accreditation decision. Furthermore, the CDM Project Design Document and the methodologies for measuring a project's climate benefit approved under the CDM can be utilised. ${ }^{24}$ 
The decisions taken in Montreal will help speed up the process of establishing JI 2nd track projects especially if the funds pledged to support the work of the JISC will come forward as indicated.

\section{Funding for developing countries}

Two of the three financial mechanisms originating from the Marrakesh Accords still remained to be operationalised in Montreal: the Adaptation Fund (AF) and the Special Climate Change Fund (SCCF). The former aims at supporting vulnerable developing countries to adapt to the impacts of climate change, whereas the latter addresses both mitigation and adaptation activities in developing countries. How these funds are intended to function was discussed during two separate agenda items as the SCCF relates to the Convention whereas issues regarding the AF relate to the Protocol. Once in operation, the funds could indeed drive activities of adaptation and possibly economic diversification in non-Annex I Parties: financial support of USD 34 million has been pledged by Annex I Parties to the SCCF, and the AF receives a share of proceeds of $2 \%$ of the CERs generated under the CDM as well as voluntary contributions.

However, achieving agreement in these areas proved to be difficult because the disagreement over the funds is intimately linked to concerns regarding the operation of the Global Environment Facility (GEF), the entity charged with operating the climate regime's financial mechanism. The SCCF, just like its Convention sister fund, the Least Developed Countries Fund (LDCF), is located in the GEF. Some developing countries feel that the GEF requirement for co-financing is favouring countries that already receive the bulk of foreign direct investment flowing to the global South. The recent development at the GEF, to adopt a Resource Allocation Framework that earmarks funds to certain countries, has thus been met with great resistance by some developing countries. A communication document between the COP and the GEF has been agreed on that requests the GEF to clarify these issues. A recent report by the GEF was taken note of under the $\mathrm{COP}$ and views were invited to develop additional guidance to the GEF on the SCCF.

The SCCF was therefore not fully operationalised in Montreal. Despite considerable progress on the draft text regarding the functioning of the SCCF,
Parties did not come to an agreement over the role of 'economic diversification activities' in the fund, a recurrent demand by OPEC countries that aim to be compensated for alleged losses of oil revenues due to climate protection policies. As a result, the bracketed text of the last meeting of the subsidiary bodies of the climate regime in May 2005 (SB 22) ended up being passed on to the next meeting (SB 24) without any changes.

Concerns regarding the AF are even more complex. According to developing country Parties, the substantial political power that the US can exercise in the decision-making processes at the GEF may make it inappropriate for managing a fund that is driven by the Kyoto Protocol, which the US has not ratified. Nevertheless, the EU supported the location of the fund in the GEF to ensure that project activities are coordinated with the activities under both the SCCF and the LDCF. In addition, the EU favoured the co-financing instrument that is generally applied by the GEF. At the end of lengthy formal and informal discussions, an agreed text was forwarded to the MOP laying out initial guidance that specified neither the location of the fund nor the procedural issues such as co-financing, costeffectiveness and eligibility criteria but called for submissions of Parties on this matter and a workshop coordinated by the Secretariat. ${ }^{25}$ Related to the AF is a completely bracketed draft Memorandum of Understanding (MoU) between the MOP and the GEF that has been passed on to SB 24. The EU and Japan had called for this MoU, but G-77 \& China found it unnecessary since the group does not want the AF located in the GEF. These two financial mechanisms will thus continue to be under heated debate.

\section{Starting the Buenos Aires Work Programme on Adaptation}

Adaptation is a cross-cutting issue across all sections of the Convention. COP 9 in Milan 2003 thus had set up a comprehensive approach dealing with adaptation concerns. From these efforts emerged the Buenos Aires Programme of Work on Adapta-

\footnotetext{
25 Draft decision -/CP.11, Initial guidance to an entity entrusted with the operation of the financial mechanism of the Convention, for the operation of the Adaptation Fund, FCCC/SBI/2005/L.32, 6 December 2005.
} 
tion and Response Measures, adopted at COP 10, which called for the Subsidiary Body for Scientific and Technological Advice (SBSTA) to develop a five-year programme of work on scientific, technical and socio-economic aspects of vulnerability and adaptation to climate change. Parties have since submitted their views and a three-day workshop was held in Bonn in October 2005 to provide guidance to COP 11.

The objective of the programme of work as adopted at COP 11 is to 'assist all Parties, in particular developing countries, to improve their understanding and assessment of impacts, vulnerability and adaptation, and to make informed decisions on practical adaptation actions and measures'. ${ }^{26}$ The programme's scope contains two thematic areas: impacts and vulnerability; adaptation planning, measures and actions, and two crosscutting issues: methodologies, data and modelling; integration into sustainable development. The programme also covers promoting understanding and the development and dissemination of measures, methodologies and tools for economic diversification aimed at increasing economic resilience and reducing reliance on vulnerable economic sectors.

To achieve the aims of the programme, SBSTA had elaborated a seven-page draft indicative list of activities for information gathering, analysis and dissemination. ${ }^{27}$ SBSTA 24 (May 2006 in Bonn) is to further elaborate on this list, decide on the timing and the possible role of experts in the implementation. Subsequent SBSTAs are to develop guidance for future actions based on the results of the initial activities. SBSTA 28 (2008) is to establish the timing and modalities for these further actions. At COP 16 (2010) a review and report is to be submitted.

26 Draft Decision -/CP.11, Five-year programme of work of the Subsidiary Body for Scientific and Technological Advice on impacts, vulnerability and adaptation to climate change, FCCC/CP/2005/L.3, 9 December 2005.

27 Scientific, technical and socio-economic aspects of impacts, vulnerability and adaptation to climate change, Draft conclusions proposed by the Chair, FCCC/SBSTA/2005/L.30, 7 December 2005.

28 For a discussion of these concerns and reform proposals see, for example, Michaelowa, CDM: current status and possibilities for reform, Hamburg 2005.

29 Draft decision -/CMP.1, Further guidance relating to the clean development mechanism, FCCC/KP/CMP/2005/L.7 8 December 2005.

\section{Improvement - reforming the CDM}

Arguably the key element on Dion's 'Improvement' agenda was the CDM, which allows industrialised countries to acquire CERs generated by climate protection projects in developing countries and count these towards their Kyoto targets. In contrast to JI, the Marrakesh Accords had mandated a 'prompt start' for the CDM and the first project had already been registered on 28 November 2004. However, there have been an increasing number of voices in the international climate policy arena calling for improvements to the way the mechanism functions. On the one hand, critics complain that the process leading to the registration of a project and the issuance of CERs has become too complex and costly. Furthermore, there have been complaints that projects are concentrating in a few countries only and that the project types that are most likely to contribute to host countries' sustainable development, such as renewable energy, energy efficiency and transport projects, are not competitive in the CDM market and therefore in danger of becoming marginalised. ${ }^{28}$

These concerns were already raised in Buenos Aires last year, but were voiced in Montreal with enhanced urgency. Twenty-seven items were tabled during the negotiations and diplomats worked long hours to find compromises between investor and host country Parties. Following are the key decisions taken in Montreal.

Right from its inception, the CDM Executive Board (CDM EB) was insufficiently funded to carry out its work. The sponsoring of the CDM process had been promised but had not materialised. In Montreal, Parties pledged to henceforward deliver the funds needed until the CDM may become selffinancing through the share of proceeds for administrative expenses that is to be levied from CDM projects. MOP 1 also set the level for the share of proceeds: the first 15,000 CERs per year that a project yields will be charged an administrative fee of 0.10 USD each whereas each CER after that will be charged a fee of 0.20 USD. $^{29}$

The 'additionality requirement' in the CDM came once again under fire at the negotiations. Additionality demands that a project activity's emissions have to be lower than those than those that would have occurred in the absence of the project activity. The Executive Board has developed the voluntary 'Tool for the Demonstration and Assessment 
of Additionality' to clarify the requirements. However, the process of establishing whether a project is additional has been criticised by the International Emissions Trading Association (IETA) and some developing countries as being too strict and complex. The proposals made in Montreal ranged from affirming the status quo to preparing a decision for MOP 2 that would overrule the CDM EB procedure on additionality. The compromise reached was to leave the authority on additionality with the CDM EB, but to make a call for public input on new proposals to demonstrate additionality and report the outcome to MOP $2 .{ }^{30}$

Concerns were also raised over the geographic distribution of participation in CDM projects noting that particular countries, especially in Africa, are in danger of being left empty-handed. As a response to these criticisms, the MOP resolved to invite Parties' submissions on what systemic and systematic factors may constitute barriers to a more equitable geographical distribution of projects. The CDM EB is to prepare recommendations for MOP 2 on this basis. ${ }^{31}$ Furthermore, Annex I Parties were invited to increase their capacity-building activities with a view to achieving a more equitable global distribution. ${ }^{32}$

Another topic that was intensively debated was that of the newly emerging Sectoral CDM. Under a Sectoral CDM, policies and programmes may become CDM projects alongside the current singlesite projects. ${ }^{33}$ During the negotiations it emerged that non-Annex I countries see the Sectoral CDM as a way to broaden the scale of the CDM whereas Annex I countries were hesitant to embrace the idea based on their concerns of the CDM being watered down. During the MOP, countries decided to exclude 'policies' and 'standards' from the CDM but to include 'programmes' that use appropriate methodologies to ensure that emission reductions are 'real, measurable, verifiable and additional'. However, the negotiators did not agree on a definition of the term 'programme'. Furthermore, countries agreed to allow the bundling of several largescale activities at multiple sites into one project. ${ }^{34}$

In response to the request for clarification brought forth by the $\mathrm{CDM} \mathrm{EB}$, the MOP needed to deal with the role of HFC projects in the CDM. HFCprojects reduce Hydrofluorocarbons (HFC). The incineration of HFC-23 is a popular CDM-project activity as the emission reductions can be achieved quite cheaply. HFC-23 incineration at existing pro- duction sites can already generate CDM credits, but the CDM EB wanted clarity on whether incineration at new facilities was also permitted under the CDM. In Montreal, Parties were only able to agree on a definition of a 'new facility'. The issue of how to deal with them was referred to the next session of the Subsidiary Body for Scientific and Technological Advice (SBSTA) to work out recommendations for MOP 2. Concerning the issue of whether carbon capture and storage (CCS) technology can be applied in a CDM project, the MOP asked the UNFCCC secretariat to organise a workshop on this issue with the aim of having the CDM EB prepare recommendations on how to approve CCS projects as CDM projects by MOP $2 .{ }^{35}$

Affirming the future of the CDM beyond the Kyoto Protocol's first commitment period, which ends in 2012, was of broad concern at the conference. This did not depend on the CDM negotiators, though, but rather on whether it would be possible to establish a solid negotiation process for the time after 2012. The decisions finally taken in this regard, analysed above, exceeded expectations and reaffirm that the Kyoto Protocol is here to stay and to be continued after 2012. Thus, this decision also serves to bolster confidence that emission reductions post-2012 will have value - even though it is not the explicit guarantee some had hoped for.

Besides being the first of its kind, MOP 1 has made considerable headway towards making the Kyoto mechanisms operational. The adoption of the

\footnotetext{
30 Ibid.

31 lbid.

32 Draft decision -/CMP.1, Capacity-building relating to the implementation of the Kyoto Protocol in developing countries, FCCC/SBI/2005/L.35, 6 December 2005

33 See, for example, Samaniego/Figueres, 'Evolving to a SectorBased Clean Development Mechanism', in: Baumert (ed.), Building on the Kyoto Protocol: Options for Protecting the Climate. Washington, DC 2002, pp. 89-108; Figueres, Sectoral CDM: Opening the CDM to the yet Unrealized Goal of Sustainable Development, Forthcoming publication of the International Journal of Sustainable Development Law \& Policy, 2005. Sterk/Wittneben, Addressing Opportunities and Challenges of a Sectoral Approach to the Clean Development Mechanism, Wuppertal 2005.

34 Draft decision -/CMP.1, Further guidance relating to the clean development mechanism, FCCC/KP/CMP/2005/L.7, 8 December 2005.

35 Decision -/CMP.1, Implications of the establishment of new hydrochlorofluorocarbon-22 (HCFC-22) facilities seeking to obtain certified emission reductions for the destruction of hydrofluorocarbon-23 (HFC-23), FCCC/SBSTA/2005/L.27/Add.1, 6 December 2005.
} 
Marrakech Accords by the MOP brings more certainty to the Kyoto process. With the JISC being set up and ready to operate, North-North cooperation on climate-friendly projects can now begin. Increasing the CDM EB staff and providing the necessary funding for the CDM process will accelerate the approval process and eliminate the current backlog of projects.

To ensure the integrity of the CDM, the MOP resisted calls to undermine the additionality requirement. The MOP also launched a process to examine the reasons for the current inequitable geographical distribution of CDM projects and develop options to address this problem. Furthermore, the decision to include programmes in the CDM may serve to enhance the sustainable development benefits by supporting sustainable energy activities such as renewable energy and energy efficiency. Nevertheless, there is still ways to go in order to advance the sustainable development objective of the CDM. High-quality projects continue to be in need of encouragement, as the trend seems to be heading towards including CCS projects and HFC-23 incineration at new facilities. These projects are capable of reducing emissions but their contribution to local sustainability goals remains controversial. Thus the onus of bringing about sustainable development continues to be on host countries to only approve high-quality projects and on buyer countries to demand CERs from sustainable projects.

\section{Conclusions and outlook}

Only history will award the climate negotiations in Montreal their proper place. Nevertheless, the following observation appears to be justified: The Kyoto Protocol is by no means in a safe haven, but it is certainly in from the cold. The treaty is in

36 See e.g. the report of the Wuppertal Institute for WWF, Target 2020: Policies and Measures to Reduce Greenhouse Gas Emissions in the EU, available at:

http://www.panda.org/climate/EUtarget2020.

37 See http://www.fiacc.net and the various approaches described by Bodansky, Climate Commitments, Assessing the Options. Advancing the International Effort Against Climate Change, Pew Climate Center, 2005. See also Höhne/Phylipsen/Ullrich/Blok, Options for the second commitment period of the Kyoto Protocol, research report for the German Federal Environmental Agency, 2005, available at: http://www.umweltbundesamt.de. force, its mechanisms have rules and its institutions are staffed with experienced diplomats. The further development of the Protocol is not any longer dependent on one particular country, but open to a range of processes by various groups of countries. In short - the Kyoto Protocol is alive and relatively healthy.

All three 'Is' remain important: Implementation, because without effective policies at the national, regional and local level the Protocol would still fail. Only when emissions actually decrease will the capand-trade approach of the Kyoto Protocol finally prove its worth. This means that all Annex I Parties have to get down to serious business now and start implementing effective climate policies. ${ }^{36} \mathrm{~A}$ reporting procedure for such domestic activities is in place, as well as a compliance procedure to support implementation and to deter from non-compliance.

'Improvement' will also remain important. The Kyoto Protocol Parties have the necessary means at hand to continuously adapt the rules of the regime to new insights, developments and circumstances. The operation of the flexible mechanisms, for example, represents a steep learning curve for all Parties and requires constant modifications of the regime. However, the procedures for such learning processes might need to be improved. One of the most severe obstacles for faster amendments of the rules is the consensus requirement that is in place because Parties have so far not been able to agree on rules for voting.

And last, the 'Innovation' process will require substantial input in terms of time, energy, money and creativity. ${ }^{37}$ The latter should arguably play the most prominent role. Michael Zammit Cutajar, the intellectual father of the three 'Is', had originally termed the third process 'Imagination', instead of 'Innovation'. This expression may have expressed even better the difficult tasks ahead, because it captures the essence of what is required: The ability to think beyond traditional concepts of power politics and beyond positions dictated by short-term national interests.

This is true for Annex I and non-Annex I countries. Whereas the former will have to accept that substantial financial support for developing countries will be required in order to induce effective climate policies in the South, the latter will have to say good-bye to outdated concepts of 'solidarity' within the G-77 \& China - meaning that they must all be treated alike. There are substantial differ- 
ences between G-77 countries. But there are also ways of addressing those differences in a transparent and equitable manner. ${ }^{38}$

The Montreal conference initiated a number of post-2012 processes with the aim of addressing the climate challenge more adequately. Within the Kyoto track, negotiations on a second commitment period for industrialised countries were initiated and preparations for the Article 9 review of the Kyoto Protocol are underway. The latter could potentially lead to an evolution of the Protocol that enables some non-Annex I Parties to take on (other types of) commitments in the mid-term. This will also be an objective of the Convention track, the 'dialogue on long-term cooperative action'. One of the main challenges will be to conduct those negotiations separately from each other, but nevertheless to ensure that they may eventually converge.

One of the most delicate tasks of the years ahead will be to find a strategy to deal with the United States, which is engaged in the convention process but not in the Kyoto regime. It was quite visible in Montreal that the US administration had never been as isolated in the climate negotiations. Saudi Arabia in the end remained the only ally. Last minute high-level attempts by President Bush to forge a 'coalition of the unwilling' were not successful. But the US administration was not only isolated at the international level. The multitude of people and organisations from the US roaming the premises of the conference provided the distinct feeling that the Bush administration was even isolated within its own country. The close distance to US territory allowed a much wider participation of US Americans than usual. Dozens of mayors from all over the US, hundreds of environmental organisations, green business associations, religious groups and also the Inuit from the Arctic all de- manded that the US support effective climate policy and not obstruct progress of the Kyoto Protocol. Many went as far as calling on the rest of the world to go ahead without paying too much attention to the current US administration.

This image of desperate - rather than splendid isolation may have encouraged European, African, Asian and Latin American diplomats to show more courage than usual. The US delegation in the end had to budge because their position simply had become untenable. Although there is little reason to believe that the current US administration will change its attitude towards climate policy in general and the Kyoto Protocol in particular, future Presidents of whatever colour may have a very different attitude - and there is increasing climate change activity on Capitol Hill. It can safely be expected that the cap-and-trade approach of the Kyoto Protocol, largely conceived of by scientists and policy-makers from the United States, will also be the favourite model for international climate policy by a future US administration.

The next meetings, MOP 2 and COP 12, will take place from 6 to 17 November 2006 in Nairobi, Kenya. A climate conference in a sub-Saharan African country constitutes a remarkable progress of the regime. It could place developing countries' concerns firmly on the agenda - both in terms of mitigating climate change and of adapting to climate change. This could certainly be a promising start for post-2012 negotiations.

\footnotetext{
38 See e.g. Ott/Winkler/Brouns/Kartha/Mace/Huq/Kameyama/Sari/ Pan/Sokona/Bhandari/Kassenberg/La Rovere/Rahman, SouthNorth Dialogue on Equity in the Greenhouse, A proposal for an adequate and equitable global climate agreement, Eschborn 2004, see: http:///www.south-north-dialogue.net and some of the approaches listed at http://www.fiacc.net.
} 


\section{Contents}

Editorial

89

\section{ARTICLES}

The Montreal Climate Summit: Starting the Kyoto Business and Preparing for post-2012

The Kyoto Protocol's First Meeting of the Parties (MOP 1) and COP 11 of the UNFCCC

Bettina Wittneben, Wolfgang Sterk, Hermann E. Ott and Bernd Brouns

Emergency and Protection of the Environment in the 'Risk Society'

101

Rosario Ferrara

Trade and Environment: Looking beneath the Sands of Doha?

Mark Halle

Exemptions from Statutory Water Management Objectives:

Requirements, Spheres of Responsibility, Unresolved Implementation Issues

Harald Ginzky

Convergence or Divergence of National Legal and Administrative Structures? Europeanisation Effects of the Environmental Impact Assessment in Germany and England (Part 2)

Christoph Knill and Daniela Winkler

The Transfer Rule in the German Emissions Trading System

The Transfer of Emissions Allowances from Decommissioned Plants to New Facilities as a Major Incentive for Modernisation According to the German Allocation Act

Markus Ehrmann and Dominik Greinacher

\section{EU JURISDICTION}

Recent Case-Law of the European Court of Justice and the Court of First Instance

\section{Law Governing the Institutions}

Trade-related environmental measures - double legal basis

ECJ, Judgment of 10 January 2006 - Case C-178/o3

Action for annulment Commssion v European Parliament and Council of the European Union

Case Note $\cdot$ Ludwig Krämer

\section{Climate Change}

Action plan for emission trading under scrutiny by the Court

CFI, Judgment of 23 November 2005 - Case T-178/05

Infringement proceeding United Kingdom v Commission of the European Communities

Case Note · Ludwig Krämer 


\section{Air Quality}

Free lorry transit through Austria and the protection of the environment - traffic ban on the Brenner Motorway

ECJ, Judgment of 15 November 2005 - Case C-320/03

Infringement proceeding Commission v Austria

Case Note $\cdot$ Ludwig Krämer

Waste Management

Concept of 'notifier' and notifier's obligations

ECJ, Judgment of 16 February 2006 - Case C-215/04

Preliminary ruling, Marius Pedersen A/S v Miljøstyrelsen

Biodiversity and Natural Resources

Classification of a special protection area / failure to include sites

ECJ, Judgment of 23 March 2006 - Case C-209/04

Infringement proceeding Commission $v$ Austria

Directive oiseaux / réduction d'une zone de protection spéciale

Conclusions de l'Avocat Général J. Kokott présentées le 23 Février 2006 - Affaire C-191/05

Procédure d'infraction Commission v Portugal

Directive oiseaux / I'usage du pouvoir de dérogation fondé sur l'article 9(1)(c)

Conclusions de l'Avocat Général L.A. Geelhoed présentées le 16 Février 2006 - Affaire C-60/05

Procédure préjudicielle WWF Italia contre Regione Lombardi

\section{THE COMPARATIVE SURVEY}

\section{Questions on Planning and Development of Traffic Infrastructure}

Estonia $\cdot$ Kärt Vaarmari

France $\cdot$ Juliette Deslandres

Germany $\cdot$ Christiane Trüe

Italy · Anna Porporato

The Netherlands · Marlon Boeve and Jos Janssen 175

Sweden · David Langlet $\quad 176$

Switzerland · Nathalie Schneider $\quad 177$

\section{MISCELLANEOUS}

Editors and Country Correspondents

\section{$|\mathrm{J}|$ OURNAL \\ FOR E UROPEAN \\ E NVIRONMENTAL \& \\ P LANNING \\ L AW}

Publisher

Lexxion Verlagsgesellschaft mbH

Güntzelstraße $63 \cdot 10717$ Berlin · Germany

Tel.: +49 30/ 8145 06-o

Fax: +49 30/81 45 o6-22

www.lexxion.de

ISSN $1613-7272$ 